\title{
SEXUALIDAD, REPRODUCCIÓN Y CULTURA OBRERA REVOLUCIONARIA EN ESPAÑA: LA REVISTA ORTO (1932-1934)
}

\author{
Javier Navarro Navarro \\ Universitat de València \\ jnavarro@uv.es
}

\begin{abstract}
Cómo citar este artículo/Citation: Navarro Navaro, J. (2014). "Sexualidad, reproducción y cultura obrera revolucionaria en España: la revista Orto (1932-1934)". Arbor, 190 (769): a175. doi: http://dx.doi.org/10.3989/arbor.2014.769n5014
\end{abstract}

Recibido: 26 noviembre 2013. Aceptado: 24 marzo 2014.

\begin{abstract}
RESUMEN: Orto. Revista de Documentación Social, publicada en Valencia entre 1932 y 1934, es un buen ejemplo de las publicaciones culturales del movimiento obrero español, en especial del mundo anarcosindicalista. La intención de su director, Marín Civera, era que la revista actuara como plataforma de confluencia de las distintas opciones obreristas, unidas a través de las tesis del sindicalismo, contando para ello con una amplia y diversa nómina de colaboradores. En su línea de "documentación social para el proletariado", la publicación mostró un interés especial por la difusión teórica y práctica, así como el debate, en torno a la reforma sexual, vinculándose al movimiento internacional por esa causa. Junto a la batalla por una nueva moral sexual o la condena de la prostitución, se defendieron desde sus páginas los principios neomalthusianos y eugenésicos, al estilo de otras publicaciones de la época relacionadas con el movimiento libertario, como Generación Consciente-Estudios.
\end{abstract}

PALABRAS CLAVE: Anarquismo; España; Historia; Sindicalismo; Movimiento Obrero; Cultura Obrera; Sexualidad; Neomalthusianismo; Eugenesia.

\section{SEXUALITY, REPRODUCTION AND REVOLUTIONARY WORKERS' CULTURE IN SPAIN: THE JOURNAL ORTO (1932-1934)}

Copyright: (C) 2014 CSIC. Este es un artículo de acceso abierto distribuido bajo los términos de la licencia Creative Commons Attribution-Non Commercial (by-nc) Spain 3.0.
ABSTRACT: Orto. Revista de Documentación Social, published in Valencia from 1932 to 1934, is a good example of cultural magazines in the Spanish labour movement, particularly in the world of anarcho-syndicalism. Marín Civera, its editor, sought to make Orto (which had a large and diverse range of contributors) a forum for convergence between the different working-class ideologies, united by the ideas of "Syndicalism". In keeping with its aim to be "social documentation for the proletariat ", the journal took a strong interest in the spread of theory and practice, and debates on, sexual reform, linking these efforts to the international movement for that cause. In addition to the struggle for a new sexual morality and the condemnation of prostitution. Orto also defended the principles of NeoMalthusian and Eugenics, in common with other contemporary journals of the Spanish libertarian movement, such as Generación Consciente-Estudios.

KEYWORDS: Anarchism; Spain; History; Syndicalism; WorkingClass Movement; Working-Class Culture; Sexuality; NeoMalthusianism; Eugenics. 


\section{SEXUALIDAD, MOVIMIENTO LIBERTARIO Y PUBLICACIONES}

Como es sabido, el movimiento libertario español mostró desde sus orígenes -y sobre todo desde inicios del siglo $X X^{1}$ - un especial interés por los aspectos vinculados con la sexualidad y la reproducción humanas. Estos asuntos, por sí mismos, conectados entre sí o relacionados con la "cuestión femenina" o con temas como la familia, el matrimonio y las relaciones de pareja (con el famoso y polisémico "amor libre"), el naturismo, la educación o la ideología anarquista en general, recibieron una amplia atención en estos medios, tanto en su publicística (prensa, libros, folletos), como en las discusiones en asambleas o congresos, o en las charlas, conferencias y otras prácticas socioculturales (Álvarez Junco, 1991/1976, p. 281; Nash, 1981, p. 44).

Dentro del conjunto del movimiento obrero español, el interés prestado a estas cuestiones por los ácratas fue sin duda destacado, convirtiéndose en buena medida en divulgadores y difusores entre las clases populares de corrientes, ideas y prácticas existentes en estos años en el ámbito internacional. Ello no quiere decir, por supuesto, que todos los sectores libertarios coincidieran en la importancia del tema, que desde su militancia se aceptara mayoritariamente esta relevancia, o que, por supuesto, se compartieran las mismas opiniones. Por el contrario, la diversidad de posturas y actitudes fue lo habitual en este sentido, configurándose así verdaderos debates internos al respecto.

En años recientes, la historiografía sobre el anarquismo español ha ido dedicando una mayor atención a este tema, casi siempre desde su dimensión discursiva y la perspectiva de esos debates, y centrándose en la sexualidad (Cleminson, 1995, 2000 y 2008; Cleminson y Windpassinger, 2012), el neomalthusianismo (Abelló, 1979 y 2006; Masjuan, 2000 y 2002; Nash, 1984) o la eugenesia (Álvarez Peláez, 1995), así como en el marco general de recepción del pensamiento científico en el movimiento libertario desde fines del siglo XIX (Girón, 1996 y 2005). Asimismo, se ha abordado el estudio del anarcoindividualismo, corriente libertaria que en las décadas de 1920 y 1930 mostró una especial sensibilidad hacia la cuestión (Díez, 2001 y 2007). Por otro lado, el tratamiento de estos asuntos en la época aparecía a menudo vinculado, como señalábamos, con la problemática de "la mujer" y las cuestiones de género (Espigado, 2002; Nash, 1975, 1981, 1995 y 1999; Vega, 2010). Afortunadamente, el tema ha ido apareciendo también en algunos de los recientes trabajos e investigaciones sobre la cultura libertaria en España desde una perspectiva global (Aisa, 2006; Hoffmann, Joan i Tous y Tietz, 1995; Marin, 2010; Morales, 2012; Navarro Navarro, 2004 y 2010).

Un elemento fundamental en ese doble esfuerzo de difusión/controversia en torno a estas cuestiones en el mundo anarquista y anarcosindicalista fueron las publicaciones periódicas, especialmente las de carácter doctrinal y cultural, así como las colecciones de libros y folletos que dependían en buena manera de ellas. En las décadas de los veinte y treinta del siglo pasado -un período donde el interés por los temas vinculados a la sexualidad y la reproducción alcanzó una relevancia significativa tanto en el ámbito internacional como en el español (Álvarez Peláez, 1988 y 1999; Guereña, 2004, 2011 y 2013; Vázquez García y Moreno Mengíbar, 1997)- determinadas publicaciones y editoriales ácratas españolas destacaron como cajas de resonancia en ese sentido (Barona y Bernabeu, 2001; Barona, 2003). Diarios y semanarios orgánicos del ámbito confederal y libertario se hicieron eco de estas cuestiones, pero también, y especialmente, revistas de pensamiento y culturales donde aquellas tuvieron un peso específico destacado. Sobresalieron aquí, por ejemplo, cabeceras como La Revista Blanca, Ética-Iniciales y, sobre todo, Generación Consciente (1923-1928), publicación nacida en Alcoy y editada posteriormente en Valencia bajo el nombre de Estudios (1928-1937), y que tuvo en la discusión y divulgación sobre la sexualidad, el control de natalidad o la eugenesia uno de sus sellos distintivos (Navarro Monerris, 1988; Navarro Navarro, 1997a y 1997b). Otra de las publicaciones donde el tema tuvo una atención importante, aunque no de manera tan destacada y, como veremos, con un origen y una orientación ideológica algo distintos, fue la también valenciana Orto.

\section{ORTO (1932-1934) Y MARÍN CIVERA}

Orto ("Revista de Documentación Social") fue publicada en Valencia entre marzo de 1932 y enero de 1934 (Paniagua, 2001; Navarro Navarro, 1997c y 2004, pp. 219-222). Con una periodicidad mensual, alcanzó un total de veinte números ${ }^{2}$.Orto era una revista "de fondo", de carácter doctrinal, centrada en la reflexión y la divulgación de pensamiento social, aunque con una vocación de amplitud temática que le acercó al modelo de publicación cultural obrerista de esos años, en la línea de otras cabeceras también vinculadas al mundo anarquista y anar- 
cosindicalista, como las ya mencionadas Estudios o La Revista Blanca (2a época: 1923-1936). En ellas estaba presente la cultura en un sentido tradicional del término (literatura, arte, etc.), pero les caracterizaba asimismo una atención especial a determinadas cuestiones cercanas a la cultura y la sensibilidad libertarias del momento: transformación de la vida cotidiana, naturismo, sexualidad, emancipación de la mujer, divulgación científica, etc.

En Orto destacaron los temas relacionados con la organización social y económica (crítica al capitalismo, articulación de la futura sociedad posrevolucionaria, fórmulas de vertebración sindical...), pero también aparecieron de forma reiterada, y en coherencia con lo anterior (en la línea de una reflexión social amplia y global), el anticlericalismo, el pacifismo, la medicina, la literatura, el arte, la pedagogía, la ciencia, etc. Lejos de un papel secundario o testimonial, algunas de estas cuestiones -entre ellas las relacionadas con la sexualidad y la reproducción- gozaron por el contrario de una atención especial en las páginas de Orto. Asimismo, la crítica política, social o económica desde la publicación abarcó también la imagen, con las magníficas portadas y fotomontajes, reportajes fotográficos, dibujos o viñetas realizados por artistas plásticos de la talla de Josep Renau (redactor gráfico de la revista) o Manuel Monleón, y que concidirían también en Estudios.

Por otro lado, Orto se acompañó de otras iniciativas editoriales: la "Biblioteca de Orto", donde se publicaron una veintena de libros sobre los temas que se abordaban en las páginas de la revista, y los "Cuadernos de Cultura", colección donde aparecieron un total de 91 folletos de sesenta páginas, sobre una amplísima variedad de materias y dirigida (se vendían a sesenta céntimos) a un público popular y obrero (Navarro Navarro, 2004, pp. 239-241).

Tanto "Cuadernos de Cultura" como Orto fueron proyectos muy ligados a la personalidad, la trayectoria vital y las inquietudes ideológicas de su animador y director: el profesor mercantil, pensador y economista valenciano Marín Civera (1900-1975). Proveniente de la CNT y masón, Civera fue, entre otras cosas, divulgador en España de las tesis del sindicalismo, autor de diversos libros y ensayos sobre el tema y uno de los fundadores, junto al histórico dirigente confederal Ángel Pestaña, del Partido Sindicalista (Íñiguez, 2008, p. 402; Paniagua, 1979,1982 y2001; Ruiz Pérez, 2004). En opinión de Civera, el sindicalismo constituía el punto de confluencia mejorado de las distintas opciones obreris- tas existentes, aunando lo mejor de las tradiciones del marxismo y el anarquismo, y superando de esta manera sus contradicciones y la clásica división del proletariado (Civera, 1931). Civera se convirtió en difusor, a través de sus proyectos editoriales, de la obra de autores como Pierre Besnard o Christian Cornelissen y de sus planes de vertebración sindical de la sociedad posrevolucionaria, a la vez que se comprometía en la divulgación correcta de las diferentes ideologías del movimiento obrero que habían nutrido esa síntesis sindicalista. Era frecuente en la revista referirse a la vocación ecléctica, flexible y antidogmática de la publicación dentro de las filas obreristas, en lucha permanente contra el "sectarismo". Esta orientación editorial abierta permitió que aparecieran en Orto artículos de marxistas y anarquistas (y a su vez de distintas corrientes), sindicalistas, etc., tal como se afirmaba en el segundo número (abril de 1932): “...publicaremos lo que vayamos recibiendo de todos los hombres de relieve internacional que militen en el campo socialista en sus más variadas manifestaciones".

No es de extrañar desde estos planteamientos que la nómina de autores en Orto fuera extensa y variada ideológicamente, aunque siempre en lo esencial dentro de la izquierda obrerista. En sus páginas escribirían anarquistas como Camilo Berneri, Max Nettlau, Gastón Leval o Émile Armand; sindicalistas moderados que acabarían fuera de la CNT, como Ángel Pestaña o el propio Civera; comunistas ortodoxos o heterodoxos como Lucien Laurat, Henri Barbusse, Josep Renau o Andreu Nin; o figuras provenientes del republicanismo federal o del socialismo como Hildegart Rodríguez o Matías Usero Torrente, entre otros.

Todo ello no significa que Orto se situara al margen de la orientación ideológica y de las opciones estratégicas de su director. Afín a Ángel Pestaña (amigo sobre quien ejercería una nada desdeñable influencia intelectual y a quien daría a conocer la obra de los teóricos sindicalistas europeos ya citados -Paniagua, 2001: LVII), partidario y difusor como vimos de las tesis sindicalistas, y todavía dentro de la CNT al inicio de esta aventura editorial, Civera se encontraba -como el propio Pestaña o Joan Peiró - entre quienes serían derrotados en la batalla por el control del sindicato confederal a inicio de los años treinta. Hostil al sector partidario del insurreccionalismo revolucionario, finalmente triunfante en la CNT durante la Segunda República, cercano al treintismo y al movimiento de Sindicatos de Oposición, Civera daría 
junto a Pestaña un paso más con la creación del Partido Sindicalista (con la intención de traducir electoralmente la fuerza social de la CNT y el propósito de utilizar la vía parlamentaria), organización a la que dedicaría sus esfuerzos a partir de su fundación en 1934 y cuya presidencia asumiría tras la muerte de Pestaña en 1937.

No disponemos de datos precisos sobre la tirada de la revista, pero sí nos constan las dificultades económicas por las que atravesó. Civera acabaría costeando de su propio bolsillo esta aventura periodística y los otros proyectos editoriales, hasta la desaparición definitiva de todos ellos en $1934^{3}$. Desde Orto se hizo mención en varias ocasiones a la falta de apoyos y, sobre todo, a la hostilidad de los sectores anarcosindicalistas más doctrinarios, a los que se culpaba de una auténtica campaña de acoso y derribo hacia la publicación en nombre de una "mal entendida conciencia libertaria" y "un atavismo intolerante y fanático, bien incompatible con las ideas libres que dicen practicar" (Orto, no 14, abril de 1933). Este boicot "faísta" resultaría especialmente dañino para una publicación que se dirigía hacia una audiencia sindical y obrerista. A diferencia de la revista cuyo éxito trató en buena medida de imitar -Estudios,Orto no consiguió situarse (pese a sus apelaciones al "eclecticismo") al margen de las batallas internas del cenetismo español. En el fragor de esa pugna, el preciso alineamiento de Civera en las posiciones sindicalistas y pestañistas le granjearía la enemistad de los sectores más definidamente anarquistas. Por su parte, los elogios de la prensa treintista del momento (Sindicalismo, El Combate Sindicalista) no serían suficientes para garantizar la continuidad de Orto, que, por otro lado, tampoco llegó a ser nunca una publicación oficial de estos medios ni actuó como su órgano de expresión. Orto fue a la postre un proyecto muy personal de Civera, quien marcó en exclusiva su línea editorial, reflejándose asimismo en sus páginas las inquietudes y temáticas que más le preocupaban en aquellos años: análisis de la crisis del capitalismo en plena década de los treinta, articulación doctrinal del sindicalismo, difusión de la cultura radical y obrerista, defensa del movimiento de reforma sexual, etc.

La difusión de un bagaje suficiente de conocimientos en los planos social, económico, cultural, científico y técnico entre la clase obrera, para garantizar su capacitación de cara a la organización de la producción y de la futura sociedad posrevolucionaria en general, constituía una tarea prioritaria en el pensamiento de Civera y los sindicalistas. En Orto, definida como "Revista de Documentación Social", y también en proyectos como "Cuadernos de Cultura", se reiteraba una y otra vez esta función utilitaria y de servicio a la educación de los trabajadores. Pero su propuesta no se limitaba solo a la difusión doctrinal entre el proletariado de nuevos modelos globales de organización económica y social, sino que pretendía abarcar también la discusión en torno a valores, actitudes, hábitos y prácticas que articularían la vida del individuo en la futura sociedad posrevolucionaria, dibujando así los contornos múltiples de una cultura que se pretendía alternativa al sistema capitalista. Más allá de tácticas o programas políticos concretos, y en nombre de un sustrato cultural común al movimiento obrero, de la confianza en el poder redentor de la cultura, y de unas inquietudes transformadoras y alternativas a la sociedad burguesa y capitalista, podía configurarse en teoría un terreno afín compartido por estas diversas opciones en torno a cuestiones como el papel de la ciencia, la secularización de costumbres, la sexualidad, la vida familiar o la relación con la Naturaleza, entre otras. Con opiniones distintas, sí, pero que muchas veces no respondían a estrictas filiaciones ideológicas o partidistas. En definitiva, para el proyecto de confluencia revolucionaria civeriano (bajo el paraguas del sindicalismo), el ámbito cultural se presentaba así como un marco donde resultaba más visible y fecunda esa convergencia, esbozándose así desde las páginas de la revista los perfiles de una (posible) cultura obrera compartida que superara las fronteras de culturas políticas afines.

\section{SEXUALIDAD Y CONTROL DE NATALIDAD: DEBATE Y DIFUSIÓN}

Orto coincidía, en este enfoque amplio y global de la vida social y la importancia en ella de actitudes vitales y culturales nuevas y distintas, con otra revista ya mencionada, la también valenciana Estudios (1928-1937), que hizo -de manera más clara y acentuada que en el caso de Orto- de esta reflexión sobre la transformación revolucionaria de la cotidianeidad su sello distintivo. Un factor de similitud con Estudios -además de esa apelación "ecléctica" ya comentada- era la atención prestada a temas como la divulgación científica y a la ciencia en general, el pacifismo y el humanismo, y, sobre todo, la sexualidad, el neomalthusianismo y control de natalidad, la eugenesia y la "maternidad consciente". En torno a estos últimos asuntos, las opiniones mayoritarias en Orto, como veremos, concidían en lo sustancial con las de Estudios, con quien se com- 
partían además diversos colaboradores sobre estas cuestiones, como es el caso del médico anarquista alavés Isaac Puente.

Lógicamente, más allá de inquietudes por temas similares y de la convicción sincera de la importancia de su difusión y debate para la "documentación social", cabe intuir también que la apuesta de Orto por estos temas respondía al deseo de imitar el éxito comercial, por un lado, y, por otro, el ascendiente y el prestigio de Estudios en los medios populares y obreros, no específicamente libertarios. La atención a la "cuestión sexual" se debía también sin duda al creciente interés por el tema en la España de entreguerras, y por supuesto a nivel internacional y al calor de los debates existentes al respecto. Asimismo, ideológicamente, en el peso de esta cuestión en las páginas de Orto la influencia libertaria resultaba evidente. Los ácratas fueron decididamente el sector del movimiento obrero español más implicado y preocupado en el debate y difusión en torno a estos temas, por encima de los socialistas (Luis Martín, 2009).

Pero tampoco hay que desestimar aquí que, junto al innegable propósito político y educativo-divulgativo, figurara también la intención de utilizar el tema sexual como factor de atracción hacia la revista o hacia sus colecciones de libros y folletos, hecho innegable desde el punto de vista comercial, como demostraba el éxito de los títulos sobre sexualidad editados por Estudios (Navarro Navarro, 1997a y 2004, pp. 237-239), con llamativas portadas con desnudos a todo color diseñadas por artistas como Josep Renau o Manuel Monleón. Con ello se pretendía atraer también quizás a un tipo de lectores interesados por el tema, sin otra derivación ideológica, o por el consumo de un material que en otros casos combinaba su carácter semipornográfico con una envoltura de aparente divulgación científica, utilizando así el tirón de la "cuestión sexual" en estos años como reclamo de la publicación y sus colecciones (Álvarez Peláez, 2004). La presencia de títulos de los que se anunciaban ante todo la presencia de ilustraciones, fotos y otro material gráfico, y con temas a menudo relacionados con las "perversiones" sexuales, hace pensar que a veces primaban estos objetivos comerciales o publicitarios.

El peso en Orto de las cuestiones relacionadas con la sexualidad y la reproducción humanas es importante cuantitativa-por el elevado volumen de artículos $^{4}$-y cualitativamente, por la calidad y profundidad de los mismos, así como por el prestigio de sus autores en estos medios. Aun lo fue mayor en el caso de la "Biblioteca Orto" y en la colección "Cuadernos de Cultura". En la primera aparecieron obras de Hildegart Rodríguez (con títulos como Paternidad voluntaria o Cómo se curan y cómo se evitan las enfermedades venéreas), Émile Armand (Sexualismo revolucionario -amor libre-, o Libertinaje y prostitución), Luis Huerta (Prostitución, abolicionismo y mal venéreo), N. Tarassov (El proletariado ante el sexo), o P. B. Tarnowski (Perversiones sexuales). Por lo que se refiere a los "Cuadernos", editados entre 1930 y 1933 en Valencia (este último año también en Madrid), al menos 8 de los 91 títulos tenían relación con la sexualidad, y otros tantos más con cuestiones que se solían asociar discursivamente, como la familia, la higiene, la salud, etc., y en los que abundaban referencias al tema. En cuanto a los primeros, fueron los siguientes (los títulos vienen precedidos por su número dentro de la colección):

\section{HILDEGART, Sexo y Amor.}

41. HILDEGART, La Revolución Sexual.

56. POCH Y GASCÓN, Amparo, La vida sexual de la mujer. 60. MAC CABE, José, El simbolismo sexual en las religiones.

70. FIELDING, William J., La educación sexual del niño (Lo que deben saber todos los niños).

75. VALENTÍ CAMP, Santiago, Hellen Key o la libertad de amar y la mujer de mañana.

78. HUERTA, Luis, Natalidad Controlada (Birth-Control).

83. FIELDING, William J., El sexo y sus manifestaciones históricas.

Aunque la influencia libertaria fuera la matriz y el hilo conductor del interés de Orto por estos temas (junto con el referente de Estudios), la diversidad y multiplicidad de autores fueron las notas dominantes en sus páginas. Hallamos aquí colaboradores afines al campo ácrata, como el médico vasco Isaac Puente, muy influyente en estos medios -autor del folleto El comunismo libertario, de amplia repercusión en esos años- y figura clave en la difusión de estos temas entre los círculos confederales y anarquistas hasta su ejecución por parte de los franquistas en los albores de la guerra; Amparo Poch y Gascón, una de las futuras fundadoras de Mujeres Libres; el anarquista italiano Camilo Berneri(asesinado en Barcelona en mayo de 1937) o el escritor anarcopacifista rumano Eugen Relgis. También encontramos paralelamente a propagandistas de estas nuevas ideas en las publicaciones obreras, y relacionados con el socialismo, como los muy prolíficos Luis Huerta(maestro asturiano, pedagogo vinculado a 
la Escuela Nueva y a la FETE-UGT, higienista y gran divulgador de las tesis eugénicas) o la precoz Hildegart Rodríguez, incansable escritora en torno a estos temas, primero desde las filas del PSOE y vinculada poco antes de su trágica muerte en 1933 (a los dieciocho años de edad, a manos de su madre, Aurora Rodríguez, quien había diseñado su nacimiento y controlado su temprana y amplia educación como parte de un experimento social. Cf. Huertas, 2008) al republicanismo federal. En Orto escribió también el Dr. César Juarros, adscrito al republicanismo conservador, divulgador del psicoanálisis en España, presidente de la Sociedad de Abolicionismo de la Prostitución y diputado a Cortes por la Derecha Liberal Republicana en las elecciones de 1931, y que ya había colaborado en las páginas de Generación Consciente en la década de los veinte.

Asimismo, se registra en las páginas de Orto un claro alineamiento -como muestran los nombres que acabamos de citar- con el movimiento de reforma sexual europeo de entreguerras, con textos y colaboraciones de conocidos científicos partidarios de esta causa y de la difusión de los principios neomalthisianos y eugenésicos, como los doctores Havelock Ellis o Magnus Hirschfeld. Ambos eran los principales animadores de la "Liga Mundial para la Reforma Sexual sobre Bases Científicas", la Weltliga für Sexual Reform promovida por Hirschfeld desde inicios de la década de los veinte. Por lo que se refiere a su sección española, esta se fundó en 1932. Su secretaria fue la ya mencionada Hildegart Rodríguez (vinculada con la Liga Mundial a través sobre todo de Ellis) y en ella estuvieron presentes también los ya citados Juarros (vicepresidente) y Huerta (director de su sección de "Pedagogía Sexual"), entre otros, y en un primer momento Gregorio Marañón como presidente. La Liga contaba con una revista, Sexus, y se encargó de la puesta en marcha de las Primeras Jornadas Eugénicas Españolas en 1933, continuación del Primer Curso Eugénico español que suspendió la autoridad gubernativa en 1928, durante la dictadura de Primo de Rivera (Álvarez Peláez, 1988; Barrachina, 2004; Cleminson, 2003; Del Cura y Huertas, 2004; Glick, 1981; Noguera y Huerta, 1934; Sinclair, 2007). Por su parte, la sección valenciana, descrita en Sexus como "la más antigua de las organizadas dentro de la Liga Española para la Reforma Sexual" contaba al parecer con un miembro destacado, delegado asimismo a cargo de su sección legal: ni más ni menos que el propio Marín Civera (Cleminson, 2003, p. 120).
Aunque la mayor parte de los colaboradores de Orto coincidían con lo esencial de los postulados de este movimiento por la reforma sexual, su origen político diverso conducía a perspectivas diferentes sobre la cuestión. El Dr. Isaac Puente, por ejemplo, rechazó en 1932 la invitación a formar parte de la ya mencionada sección española de la Weltliga, pese a aprobar la mayoría de sus objetivos, reprochándole no obstante su reformismo y conformismo social burgués (Nash, 1984, p. 321; Cleminson, 2003, pp. 117-118). Por otra parte, entre los mismos anarquistas, las diferencias serían constantes entre, por ejemplo, los defensores de la monogamia y la "unión libre", y aquellos partidarios de la teoría de la "camaradería amorosa" de Émile Armand y los anarcoindividualistas.

Sin embargo, pese a estas divergencias de enfoque y la diversa procedencia política de sus colaboradores, en el tratamiento de la "cuestión sexual" predominó en Orto el deseo de reunir en sus páginas una muestra significativa de aquellos autores que, desde posiciones distintas dentro de la izquierda, mostraban una preocupación particular sobre el tema y la necesidad de la "reforma sexual", y que actuaban dentro de sus opciones ideológicas como promotores y activos publicistas de la cuestión. El objetivo común era contribuir a la difusión entre el proletariado de un mayor conocimiento del tema sexual y sus implicaciones. Todo ello partiendo de diversas consideraciones, compartidas también por sus diferentes colaboradores. En primer lugar, la constatación de la importancia tanto del hecho sexual como del reproductivo en la vida humana, algo que se señala que no siempre había recibido la suficiente atención en la tradición socialista.

Asimismo, se subraya que la cuestión no puede desvincularse de asuntos como la necesidad del control de natalidad (neomalthusianismo), la mejora paulatina de las condiciones de reproducción de la población (eugenesia), la crítica a la doble moral sexual y la prostitución, el debate sobre el aborto, el rol social de las mujeres, la medicina o, en menor medida en el caso de Orto, el naturismo. Todos estos temas aparecen entrelazados, difícilmente separables e inexorablemente unidos a la cuestión sexual.

Los colaboradores de Orto coinciden en una común crítica al tratamiento de la sexualidad en la sociedad capitalista y burguesa, fuente de innumerables problemas en la vida social y de contradicciones: represión de la sexualidad, pero mercantilización del "apetito sexual" y rechazo del control de natalidad; 
oposición a la educación sexual e incremento por tanto de las enfermedades venéreas; condena de la prostitución, pero puesta en marcha de su reglamentación, etc. El resultado: un panorama catastrófico en la vida sexual, cuyas peores consecuencias recaen sobre todo en las clases populares y que hace necesaria una solución específica si se busca una nueva sociedad más justa e igualitaria: "El mundo se debate en una crisis no solamente social, sino también sexual. En muchos aspectos, los factores sociales y los factores sociales aparecen íntimamente ligados" (Hirschfeld, no 18, noviembre de 1933).

La educación sexual y la formación de un individuo "consciente" (término repetido una y otra vez, conformando auténticos lemas: "generación consciente", "maternidad consciente", dibujando así un maridaje con la vieja apelación obrerista al "obrero consciente") de su sexualidad es otro de los puntos de coincidencia en la mayoría de autores de Orto, convirtiéndose en una preocupación central, al igual que ocurría en otras publicaciones libertarias españolas de la época sensibles a estas cuestiones (Nash, 1981, p. 56).La apelación a la educación sexual es reiterada, convirtiéndose incluso en clave argumentativa central en este ámbito y en recurso para resolver posibles contradicciones discursivas (por ejemplo, en el caso de la eugenesia). A través de esta formación, el individuo podrá asumir su deber social tanto en la producción como en la reproducción colectiva de una nueva sociedad.

Desde los postulados básicos descritos, se dibuja a partir de las colaboraciones aparecidas en Orto sobre la cuestión una especie de programa mínimo, a pesar de las distintas modulaciones ideológicas y las diferencias de criterio existentes sobre diversos temas. Se trata, como señalábamos, de un espíritu afín en lo esencial al movimiento de reforma sexual, y cuyos parámetros venían a resumirse precisamente en el decálogo de "fines principales" propugnado por la Liga Mundial, citados en distintos artículos publicados en la revista y buena síntesis de las preocupaciones y propuestas realizadas en este ámbito desde las páginas de la publicación: igualdad política, económica y sexual de hombres y mujeres; separación del matrimonio (y especialmente del divorcio) de la Iglesia y del Estado; control consciente y responsable de la procreación; mejora progresiva de la raza a través de la aplicación práctica de las doctrinas eugénicas; protección para madres solteras e hijos ilegítimos; actitud racional ante las personas sexualmente anormales y especialmente hacia los homosexuales; prevención de la prostitución y de las enfermedades venéreas; consideración de las actitudes anormales del impulso sexual como fenómenos más o menos patológicos y no como crímenes, vicios o pecados; asimilación de las relaciones sexuales entre adultos responsables -con mutuo consentimiento y sin que medie infracción de los derechos sexuales de la otra persona- como actos meramente privados; y educación sexual sistemática.

Al examinar las colaboraciones sobre este tema en las páginas de Orto, queda claro lo íntimamente relacionadas que están todas estas preocupaciones. Ningún artículo suele centrarse en un único punto, y existe la intención de abordar globalmente todos los aspectos vinculados a la cuestión. Por otro lado, y a pesar de la inquietud específica por el "problema sexual", a menudo es difícil desligar en algunos de estos textos el sexo de la reproducción, y se suele abordar el primero exclusivamente desde la perspectiva de la segunda. Tal como señala en la revista el escritor anarcopacifista rumano Eugen Relgis:"La revolución sexual consiste simplemente en la aplicación de los principios eugénicos y en el reconocimiento de la ley de población del malthusianismo" (Relgis, no 20, enero de 1934), mostrando así claramente, por otra parte, el peso que tenía en este momento el binomio neomalthusianismoeugenesia, con un clara tendencia hegemónica de esta última en el discurso libertario sobre esas cuestiones a inicios de los años treinta (Cleminson, 2008, pp.108-128). En todo caso, como afirma Mary Nash, y al menos en el caso ácrata, fue cada vez más común en este período "la necesidad de una desvinculación de las relaciones sexuales de la procreación" (Nash, 1984, p. 323).

Asimismo, tampoco encontramos en la publicación un importante número de artículos dedicados específicamente a la problemática de las mujeres (rol social, laboral, etc.) y la cuestión de género desde otras aproximaciones que no sean las vinculadas a la sexualidad y la reproducción. Escasean los textos con un enfoque feminista, o que planteen una reflexión global sobre el papel de las mujeres en la sociedad. Esta solía integrarse en el debate sobre la sexualidad, tal como ocurría a menudo incluso en los medios obreristas más sensibilizados por esta cuestión, como es el caso de los anarquistas ${ }^{5}$. A veces encontramos afirmaciones aparentemente sorprendentes en algunos artículos de la revista, y que servían asimismo como rechazo del "feminismo burgués", también en este caso de Eugen Relgis ( $n$ o 20, enero de 
1934): "Las cualidades morales y espirituales de la mujer no pueden hallar su expansión en el cuadro artificial de la vida del Estado sino en el cuadro natural de la especie y de la familia".

\section{UNA “NUEVA MORAL SEXUAL”}

Es un lugar común en las colaboraciones aparecidas en Orto la alusión a la importancia de un cambio en la moral sexual. El objetivo es intentar educar, imbuir al individuo de la futura sociedad revolucionaria de una "nueva moral sexual" más racional y responsable: "Una política sexual no tendrá eficacia si no se fundamenta sobre el derecho sexual, y este no subsistirá mientras no construyamos una verdadera y pura moral sexual" (Varela, no 4, junio de 1932). Es una nueva ética, auténticamente natural y racional, libre de la tutela dañina de la Iglesia y el Estado. Pero, al mismo tiempo, se suele precisar que no se trata de promover un mero libertinaje sexual desprovisto de afecto o carga "espiritual". Esta última idea, la necesidad de desmarcar la nueva moral sexual de la libre promiscuidad, es prácticamente unánime entre los colaboradores de Orto, como había sido habitual antes en los medios obreristas, proclives a un cierto puritanismo (Álvarez Junco, 1991/1976, pp. 298-299), y seguía siendo mayoritario en publicaciones similares de la década de los treinta. Como ya vimos, ideas diferentes, como las de la "camaradería amorosa" de Émile Armand o -aunque en un sentido distinto- el "amor plural" de Han Ryner, a pesar de su difusión (también desde Orto y sus colecciones de libros) no hallaron gran número de partidarios, fuera de los círculos más próximos al anarquismo individualista. Discursivamente, fue más general la tendencia a una cierta 'espiritualización' del amor y de las relaciones de pareja, y en la práctica la existencia de relaciones monógamas.

En lo que todas las colaboraciones coinciden es en la consideración de la necesidad de una nueva actitud ante la sexualidad como un paso más en el camino hacia la superación individual y colectiva. Esta nueva moral se debe fundamentar, en primer lugar, en la igualdad ante el hecho sexual del hombre y la mujer, y en la colaboración entre ambos: “...el nuevo principio coordinador de la colaboración de sexos, en cuyas manos está el futuro poder del mundo" (Huerta, no 3, mayo de 1932). De ahí la insistencia en la educación en este ámbito, especialmente de la mujer, tanto por su papel protagonista en la maternidad como por su marginación histórica. El respeto mutuo y la acep- tación del principio de la libertad de elección deben convertirse en principios rectores del nuevo comportamiento sexual.

Por ello, el fenómeno de la prostitución aparece en el punto de mira de todas las críticas y la prueba clara, tanto de la explotación/humillación de la mujer como de la perversión del hecho sexual en la sociedad capitalista. El tema, desde luego, no era nuevo (Álvarez Junco, 1991/1976, pp. 292-293, Guereña, 2003), pero en las páginas de Orto, como en otras publicaciones con inquietudes temáticas similares, adquiere una importancia considerable, ya que, entre otras cosas, permitía relacionarlo con cuestiones como la miseria y la crisis inherentes al sistema capitalista, asuntos que en el contexto de la depresión económica de la década de los treinta estaban muy presentes en la revista. En general, se apoya la abolición de la reglamentación de la prostitución por parte del Estado, polémica bastante extendida en aquellos años. Se secunda esta campaña en varios puntos. Por un lado, se resalta la vergüenza que supone el reconocimiento oficial de la prostitución. Por otro, se reclama el derecho de elección de la prostituta, así como la puesta en marcha de campañas de difusión de los medios de profilaxis venérea: desde Orto y otras publicaciones y sectores preocupados por el tema se relacionaba directamente la prostitución y el catastrófico comportamiento sexual imperante, con la propagación de las enfermedades venéreas, verdadera obsesión del momento.

\section{NEOMALTHUSIANISMO Y EUGENESIA}

La sexualidad queda unida en gran medida en el discurso presente en Orto, aun con sus diferentes modulaciones, al binomio neomalthusianismoeugenesia, que se convierte en el punto central de la argumentación en este ámbito. En efecto, todos los colaboradores de la publicación ven en la aplicación generalizada de estos principios la garantía del funcionamiento armónico de la nueva sociedad, de una manera similar a lo que sucedía en aquellos años en la revista Estudios, donde la atención por estos temas resultaba central (Navarro Navarro, 1997a, pp. 85-117).

El proceso de penetración del neomalthusianismoy la eugenesia en el mundo cultural obrero español en general, y anarquista en particular, al menos desde los tiempos de Salud y Fuerza (1904-1014), fue un fenómeno lento, complejo y no exento de resistencias. Pero a la altura de la década de 1930 se había producido ya una cierta consolidación de aquellos sectores 
sensibles a esta cuestión en el mundo obrerista (especialmente libertarios), que, aun siendo minoritarios, habían conseguido afirmar algunas plataformas de expresión, una presencia en la prensa y en el mundo editorial, y un cierto ascendiente y prestigio en estos medios. Publicaciones como Generación ConscienteEstudios se declaraban abiertamente neomalthusianas, integrando en su ideario la lucha por el control de natalidad y acompañándolo incluso de la difusión de todo tipo de información sobre la planificación familiar entre la clase obrera ${ }^{6}$. La línea marcada por estas cabeceras tenía como prioridad hacer asequible al proletariado todos los conocimientos existentes sobre el tema, justificándolos racionalmente y realizando una activa campaña por su divulgación. Cabe integrar plenamente a Orto en este contexto y en esa corriente.

Con su aceptación de la necesidad del birth control, la revista presentaba una opinión más o menos común, o al menos mayoritaria entre sus colaboradores. Siguiendo el hilo de esta argumentación, la sobrepoblación existente en la sociedad capitalista no engendra más que miseria, hambre y guerras, en una vorágine paulatina de agotamiento de los recursos, y tampoco permite su superación, porque según un lema corriente en la época: "La miseria no engendra rebeldes". El control de los nacimientos es la única salida posible, tanto en la sociedad actual como en la futura: "El malthusianismo no es derrotado siquiera por la revolución social triunfante" (Hildegart, no 2, abril de 1932). Lo más racional, consecuente y responsable es la maternidad consciente ("Sed madres conscientes de familias poco numerosas". Cf. Drysdale, no 5, julio de 1932), voluntaria y selectiva. Y esta responsabilidad en la reproducción debe contemplar también criterios eugénicos, es decir, la selección artificial y racional de los nacimientos procurando una mejora paulatina de la especie, evitando la perpetuación de rasgos y elementos negativos y favoreciendo por el contrario la de los positivos.

Desde las páginas de la revista, la eugenesia se presenta como un esfuerzo complementario al control de natalidad, que pretende mejorar racionalmente la vida humana, haciéndola más digna y autosuficiente y menos presa del sufrimiento y el dolor. Tal como se ha señalado para el caso de su presencia en el discurso anarquista sobre materia sexual a la altura de la década de los treinta (Cleminson, 2008), la eugenesia -plural en su historia, compleja y sujeta a múltiples interpretaciones y derivaciones-, lejos de tener un papel marginal, había adquirido un rol central en estas reflexiones en esos años (Álvarez Peláez, 1988,
1999). Ya no aparece como un mero anexo de la argumentación neomalthusiana, sino, al menos, como su necesario complemento.

La eugenesia era objeto de intensos debates en la época, en especial sobre el alcance de los procedimientos que permitieran una selección óptima de los nacimientos y sobre si estos debían incluir la coerción (aislamiento, esterilización, etc.) para impedir la reproducción de los "stocks negativos". Al igual que ocurrió en Generación Consciente-Estudios, y otras publicaciones obreristas españolas similares, la opinión mayoritaria en Orto(a través de los colaboradores en este terreno: Huerta, Hildegart, Puente, etc.) se mostró contraria a estos últimos métodos o su utilización por parte del Estado (lo que se vinculaba también a la filia antiestatalista y antiautoritaria libertaria). Se optaba de manera predominante por medios voluntarios y basados en la convicción y la pedagogía, aunque lo cierto es que también estuvieron presentes de una u otra manera las argumentaciones que proponían el uso de otros métodos, y que sin embargo tenderían a desaparecer en todo caso una vez conocidos los programas eugenésicos desarrollados por las nazis tras su llegada al poder en Alemania a partir de 1933.

Este es el caso de los artículos de otro autor cuyos textos tuvieron amplia difusión en Orto: el escritor anarquista rumano Eugen Relgis, apóstol del "Humanitarismo" y el pacifismo, muy citado en los medios ácratas españoles en estos años y vehemente defensor de la eugenesia. Tomando como referencia la obra del anarcoindividualista francés Manuel Devaldès (cuya obra La maternité consciente, de 1927, sería traducida y publicada por la editorial Estudios), Relgis sostenía que, aun siendo preferibles los procedimientos preventivos basados en la "generalización de la educación sexual integral”, estos podían no resultar suficientes. Frente a la eutanasia, sin embargo, la esterilización parecía el medio más razonable:

Los espartanos se mostraban sin piedad -sin falsa piedad- cuando arrojaban a un precipicio a los niños deformes e idiotas, pero hoy, con ayuda de la ciencia, los degenerados podrían ser aniquilados humanamente, por eutanasia. Sin embargo, sería preferible, por todos conceptos, que los degenerados no naciesen y mejor aún: que no fuesen concebidos. Ahora bien, esto es posible gracias a la ciencia: por medio de la esterilización de cuantos manifiesten caracteres patológicos o sufran enfermedades incurables. (...)A pesar de todo el respeto que debe tenerse para la libertad individual, los degenerados deben 
ser aislados del resto de la sociedad (locos, idiotas) o esterilizados si se les deja libres (alcohólicos, sifilíticos, etc.). La prohibición legal del casamiento de los degenerados (como ocurre en Estados Unidos) es una medida incompleta, pues el efecto eugénico queda anulado por la unión y el amor libres. La esterilización es, pues, el medio más eficaz para purificar a la humanidad. Practicada al mismo tiempo que la educación sexual integral, contribuiría a suprimir los efectos desastrosos del alcoholismo y la prostitución. Solo entonces podría ejercerse la libertad individual de una manera positiva y creadora (Relgis, no 17, octubre de 1933. En cursiva en el original).

Así pues, impedir la reproducción de determinados individuos no era crueldad, sino un acto de responsabilidad individual y colectiva en la construcción de una humanidad cada vez más sana y perfecta. Como señalábamos, la defensa de este tipo de procedimientos no fue habitual en Orto, pero tampoco, como se ve, estuvo ausente de sus páginas, lo mismo que ocurrió en Estudios. Así, Hildegart, posiblemente la colaboradora más habitual de la publicación en estos temas, afirmaba:

Creo, pues, que es muy útil la eugenesia negativa, que tiende a la esterilización de los delincuentes, por incapaces de procreación, o aun en casos no compulsorios, a crear con ello un impedimento matrimonial, lo que no impide la procreación fuera del matrimonio, razones por las cuales no es el único recomendable (..) (Hildegart, no 15, agosto de 1933).

Más adelante, como mencionábamos antes, el conocimiento de las prácticas nazis en este ámbito provocaría un "cambio de rumbo" y contribuiría a su desprestigio entre la izquierda y en el conjunto del movimiento eugenésico internacional (Cleminson, 2008, p. 127).

En Orto se optaba mayoritariamente por un maridaje entre posiciones neomalthusianas y eugenésicas. Control y selección de los nacimientos aparecían, pues, inexorablemente ("armoniosamente") unidos, y no se entendían por separado. De hecho, de manera significativa, si el primer artículo de Eugen Relgis en torno a La maternidad consciente de Devaldès se centraba, como vimos, en la eugenesia, el segundo tenía como tema la defensa del neomalthusianismo: "El equilibrio entre una y otra (neomalthusianismo y eugenesia) constituirá una selección ideal del problema de la procreación que favorecerá al progreso constante de la humanidad", con lo que la "eugénica real" no se concebía "más que asociada a la ley de población formulada por Malthus" (Relgis, no 18, noviembre de 1933). En general, se trataba de que, aunando la regulación de nacimientos con la selección científica, el proletariado pudiera tomar en sus manos su propia reproducción y, por tanto, el control de su propia vida.

El panorama de esta "nueva moral" en la procreación se complementaba con la aceptación del derecho al aborto. Este, practicado en la clandestinidad en casi todos los países capitalistas, se había convertido en una auténtica plaga social que, al igual que la prostitución, crecía al compás de las contradicciones de un sistema hipócrita que condenaba el aborto y que, sin embargo, consentía el riesgo que conllevaba para la salud de la madre su práctica en condiciones de prohibición y persecución. Desde Orto se denunció repetidamente el fenómeno, asociado comúnmente a la crisis económica del capitalismo y su intrínseca desigualdad, colocando con frecuencia al otro lado de la balanza la regulación del aborto en la legislación soviética, como ejemplo positivo de una aceptación equilibrada de este. En general se contemplaba como un auténtico derecho, pero no se apoyaba su uso sin limitaciones. Así, la médica anarquista Amparo Poch Gascón, después de defender con estos y otros argumentos en las páginas de la revista el derecho al aborto, se mostraba restrictiva en cuanto a los casos en que se debía aceptar este (reduciéndolo a aquellos casos de peligro de salud de la madre o el feto, o de violación) y afirmaba: "El embrión, desde el momento en que comienza su desarrollo, tiene derecho a la vida (...) Ha de quedar bien entendido que cuando una mujer sana ha concebido conscientemente, en virtud de un acto voluntario, la sociedad debe impedir que dicha mujer atente contra la vida de su hijo" (Poch y Gascón, no 20, enero de 1934).

\section{CONCLUSIÓN}

En definitiva, nos encontramos ante un conjunto de ideas y de valores que conforman una cultura nueva en materia sexual y reproductiva. Este complejo ideológico circulaba en los núcleos obreros españoles más interesados por el tema durante las décadas de 1920 y 1930, de una y otra tendencia, aunque, por una tradición cultural de mayor preocupación histórica por la cuestión que se remontaba al menos a inicios del siglo XX, los anarquistas resultaron los más comprometidos en la campaña. El objetivo era devolver al proletariado su integridad natural (el tema por tanto se vinculaba también con 
el naturismo: Roselló, 2003) y física, a través de una adecuada selección de su capacidad reproductora, en sentido tanto cuantitativo (control del número de nacimientos) como cualitativo (eugenesia). Eran todos aspectos de un proceso de mejora individual y colectiva, que contemplaba asimismo la construcción de un nuevo tipo de moral sexual más acorde con un desarrollo equilibrado del individuo, en camino hacia una sociedad radicalmente distinta a la existente, más justa, armónica e igualitaria.

Orto participa en esa necesidad de difundir estas concepciones entre las clases populares, en una línea muy similar a otras publicaciones como Generación Consciente-Estudios, a la que aquella tomó sin duda como referente en este ámbito, por la importancia del tema sexual y el peso de aspectos como el control de natalidad o la eugenesia, aunque en Orto no adquirieran un papel tan central como el que tenían en Estudios. En la primera estuvieron más presentes los temas relativos a la organización social o económica globales, la difusión del sindicalismo o la crítica de la actualidad política o financiera internacional, en especial por lo que se refiere a la crisis económica del capitalismo en los años treinta.

En todo caso, Orto se acercó al modelo de publicación cultural obrerista de especial éxito en los medios libertarios, al estilo de La Revista Blanca o Estudios. En el arte, la literatura o especialmente en aquellas cuestiones que hacían referencia a una transformación de la vida cotidiana, de sus hábitos o costumbres, Orto quiso reproducir el modelo culturalizante y "ecléctico" de Estudios que, en materias como la sexualidad en particular, había proporcionado a esta gran difusión, éxito y prestigio en los medios obreros. Los colaboradores de Orto en este terreno, procedentes de distintas adscripciones ideológicas (en lo esencial dentro de la izquierda obrerista), coincidieron, sin embargo, dentro de los parámetros de un programa de reforma sexual centrado básicamente en la difusión de los principales postulados de este movimiento a escala internacional. También en la recepción y difusión de los planteamientos eugénicos complementados con la aceptación del control de natalidad y los principios nemomalthusianos, tal como habían sido recibidos y asimilados hasta ese momento en los sectores del movimiento obrero más sensibilizados por estas cuestiones. La atención por el tema en las páginas de la revista dejaba ver que, al menos para sus colaboradores en este ámbito, la transformación de las pautas y comportamientos en lo sexual y reproductivo constituía un aspecto más, no secundario, de la transformación social global.

En otras cuestiones, sin embargo, el sincretismo obrerista propuesto por Civera, en realidad una defensa de sus planteamientos sindicalistas como superación de las distintas opciones ideológicas presentes en el mundo proletario, no tuvo tanto éxito. En el contexto de la pugna abierta vivida en la CNT a mediados de los años treinta, el claro alienamiento de su director -a diferencia de lo que ocurría en Estudios, sin una definición precisa en este sentido- con los postulados del sindicalismo "posibilista" le granjeó a la revista la hostilidad de los sectores más declarada y doctrinariamente anarquistas, que dominaron orgánicamente el sindicato confederal durante la Segunda República.

\section{AGRADECIMIENTOS}

El autor participa del proyecto I+D+I, HAR 201127559 (Democracia y culturas políticas de izquierda en la España del siglo XX: desarrollos y limitaciones en un marco comparativo) del Ministerio de Economía y Competitividad, financiado con fondos FEDER, y del Grupo de investigación Prometeo/2012/046, "Grup d'Estudis Històrics sobre les Transicions i la Democràcia", de la Generalitat Valenciana.

\section{NOTAS}

1 Un impulso fundamental en este sentido vendría con la publicación de la revista barcelonesa Salud y Fuerza, (1904-1914), dirigida por el libertario Luis Bulffi, órgano de la Liga de Regeneración Humana en España y receptora y difusora del control de natalidad, la "maternidad consciente" y las corrientes neomalthusianas y eugenésicas en este país, en especial entre las filas obreristas y ácratas (Abelló, 1979; Cleminson, 2008, pp. 53-75 y pp. 100-108).
2 La revista cuenta con una edición facsímil, con estudio introductorio a cargo de Javier Paniagua (2001).

3 “...Las ediciones iban tan mal que no permitían vivir de ellas, sino antes al contrario, ellas han vivido por mi sacrificio". Carta de Civera a E. Armand, 1 de agosto de 1933, Institut Français d'Histoire Sociale. En otra carta anterior (1 de marzo de 1933), Civera señalaba asimismo amargamente a

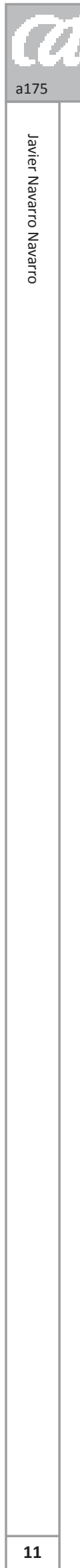

Armand: “...la gente no está por leer, prefiere lo demagógico y estridente a lo reflexivo y de estudio". Ambas citas en Paniagua, 1979, p. 68.

4 En casi todos los números de la revista (a excepción de tres de ellos, el 11, el 13 y el 19) apareció al menos un artículo sobre estos temas, y en algunos casos dos, tres (en el último, n20) e incluso cuatro (en el no16), en una publicación con una media de alrededor 
de una veintena de artículos por número, sin contar los textos dedicados a diversos aspectos de la "cuestión femenina", temática con la que habitualmente se solapaban.

5 Mary Nash que ha hecho referencia a esta cuestión, nos cuenta al respecto: “Mujeres como Trinidad Urien y María

\section{BIBLIOGRAFÍA}

Abelló, T. (1979). El neomalthusianisme a Catalunya. Lluís Bulffi i la "Liga de la Regeneración Humana" (Tesis de licenciatura inédita). Universitat de Barcelona, Barcelona.

Abelló, T. (2006). Cientifisme i anarquisme a principis del segle XX: la difusió del neomalthusianisme. Cercles. Revista d'Història Cultural, 9, 2006, pp. 10-20.

Aisa, F. (2006). La cultura anarquista a Catalunya. Barcelona: Edicions de 1984.

Álvarez Junco, J. (1991/1976). La ideología política del anarquismo español (18681910). Madrid: Siglo XXI.

Álvarez Peláez, R. (1988). Origen y desarrollo de la eugenesia en España. En Sánchez Ron, J. M. (ed.). Ciencia y sociedad en España. De la llustración a la Guerra Civil. Madrid: El Arquero-CSIC, pp. 178-204.

Álvarez Peláez, R. (1995). Eugenesia y darwinismo social en el pensamiento anarquista. En: Hofmann, B., Joan i Tous, P. y Tietz, M. (eds). El anarquismo español y sus tradiciones culturales. Frankfurt-Madrid: Vervuert-Iberoamericana, pp. 29-40.

Álvarez Peláez, R. (1999). La eugenesia española a lo largo del siglo XX. En: Romeo Casabona, C. (ed.), Eugenesia Hoy. Bilbao-Granada: Comares, pp. 87-122.

Álvarez Peláez, R. (2004). Publicaciones sobre la sexualidad en la España del primer tercio del siglo XX: entre la medicina y la pornografía. Hispania, LXIV/3, 218, pp. 947-960. http://dx.doi.org/10.3989/hispania.2004.v64.i218.174

Barona, J.L. (ed.) (2003). Ciencia, salud pública y exilio (España, 1875-1939). Valencia: Universitat de València.

Barona, J. L. y Bernabeu, J. (2001). La divulgació de la ciència entre els movi-
Luisa Cobos acusan a los hombres de no facilitar una formación cultural y una ampliación de sus conocimientos sobre las ideas libertarias a las mujeres que acudían a los Ateneos y centros obreros. En su lugar, les hablaban de relaciones sexuales y del amor libre". (Nash, 1981, p. 27). Eso sucedía en un medio cultural (el anarquista) que era,

ments socials i la seua reinterpretació en la prensa llibertària (1923-1937). En: Brumme, J. (ed.). La historia de los lenguajes iberorrománicos de especialidad: la divulgación de la ciencia. Frankfurt/ Barcelona: Vervuert-Iberoamericana, pp. 181-193.

Barrachina, M-A. (2004). Maternidad, feminidad, sexualidad. Algunos aspectos de las Primeras jornadas eugénicas españolas (Madrid, 1928 - Madrid, 1933). Hispania, LXIV/3, 218, pp. 10031026. http://dx.doi.org/10.3989/hispania.2004.v64.i218.177

Civera, M. (1931). El sindicalismo. Historia. Filosofía. Economía.Valencia: Tipografía Pascual Quiles.

Cleminson, R. (1995). Anarquismo y homosexualidad. Antología de artículos de la Revista Blanca, Generación Consciente, Estudios e Iniciales (1924-1935). Madrid: Huerga y Fierro Editores.

Cleminson, R. (2000). Anarchism, Science and Sex: Eugenics in Eastern Spain, 1900-1937. Oxford: Peter Lang.

Cleminson, R. (2003). "Science and Sympathy" or "Sexual Subversion on a Human Basis"? Anarchists in Spain and the World League for Sex Reform. Journal of the History of Sexuality, 12, 1, pp. 110-121. http://dx.doi.org/10.1353/ sex.2003.0053

Cleminson, R. (2008). Anarquismo y sexualidad (España, 1900-1939). Cádiz: Universidad de Cádiz.

Cleminson, R. y Windpassinger, G. (eds.). (2012). Anarchism and sexuality. International Journal of Iberian Studies, 24, 3, pp. 147-241.

Del Cura, M. y Huertas, R. (2004). Medicina y sexualidad infantil en la España de los años treinta. La aportación del psicoanálisis a la pedagogía sexual. Hispania, como ya mencionamos, el más preocupado por estas cuestiones dentro del mundo obrerista.

6 A este respecto, la revista Estudios divulgará entre los años 1930-1936 una ingente cantidad de métodos y técnicas de control de la natalidad, especialmente a través del Dr. Isaac Puente.

LXIV/3, 218, pp. 987-1001. http://dx.doi. org/10.3989/hispania.2004.v64.i218.176

Díez, X. (2001). Utopia sexual a la premsa anarquista de Catalunya. La revista Ética-Iniciales (1927-1937). Lleida: Pagès Editors.

Díez, X. (2007). El anarquismo individualista en España (1923-1938). Barcelona: Virus.

Drysdale, B. (1932). Natalidad controlada. Orto, 5.

Espigado, G. (2002). Las mujeres en el anarquismo español (1869-1939).Ayer, 45, 1, pp. 39-72.

Girón Sierra, Á. (1996). Evolucionismo y anarquismo en España, 1882-1914. Madrid: CSIC.

Girón Sierra, Á. (2005). En la mesa con Darwin. Evolución y revolución en el movimiento libertario en España (18691914). Madrid: CSIC.

Glick, T.F. (1981). Psicoanálisis, reforma sexual y política en la España de entreguerras. Estudios de Historia Social, 16-17, pp. 7-25.

Guereña, J-L. (2003). La prostitución en la España contemporánea. Madrid: Marcial Pons.

Guereña, J- L. (coord.). (2004). La sexualidad en la España contemporánea (1800-1950). Hispania, LXIV/3, 218, pp. 825-1042. http://dx.doi.org/10.3989/ hispania.2004.v64.i218.169

Guereña, J-L. (ed.) (2011). La sexualidad en la España contemporánea (1800-1950). Cádiz: Universidad de Cádiz.

Guereña, J-L. (2013). Les espagnols et le sexe. $X I X^{e}-X X^{e}$ siècles. Rennes: Presses Universitaires de Rennes.

Hildegart (1932). La economía mundial y el problema de la sobrepoblación. Orto, 2. 
Hildegart. (1933). Endocrinología, Delincuencia y Eugenesia. Orto, 15.

Hirschfeld, M. (1933). Al margen del asunto Noziéres. El demonio de la sexualidad. Orto, 18.

Hofmann, B.; Joan i Tous, P. y Tietz, M. (eds.) (1995). El anarquismo español y sus tradiciones culturales. FrankfurtMadrid: Vervuert-Iberoamericana.

Huerta, L. (1932). El trabajo como carácter sexual. Orto, 3.

Huertas, R. (2008). Las heridas de la ciencia. A propósito del caso Hildegart. En: Fernández, P. y Ortega, M.-L. (eds.) La mujer de letras o la letra herida. Discursos y representaciones sobre la mujer escritora en el siglo XIX. Madrid: CSIC, pp. 243-260.

Îñíguez, M. (2008). Enciclopedia histórica del anarquismo español. Vitoria: Asociación Isaac Puente.

Luis Martín, F. de (2009). Familia, matrimonio y cuestión sexual en el socialismo español. En: Lorenzo Pinar, F. J. (ed.) (2009). La familia en la historia. Salamanca: Universidad de Salamanca, pp. 261-292.

Marin, D. (2010). Anarquistas. Un siglo de movimiento libertario en España. BarceIona: Ariel.

Masjuan, E. (2000). La ecología humana en el anarquismo ibérico. Urbanismo 'orgánico' o ecológico, neomalthusianismo y naturismo social. Barcelona: Icaria.

Masjuan, E. (2002). Procreación consciente y discurso ambientalista: anarquismo y neomalthusianismo en España e Italia, 1900-1936. Ayer, 46, pp. 63-92.

Morales Muñoz, M. (2012). Rituales, símbolos y valores en el anarquismo español, 1870-1910. En: Lida, C. E. y Yankelevich, P. (coords.). Cultura y política del anarquismo en España e Iberoamérica. México D.F.: El Colegio de México, pp. 27-61.

Nash, M. (1975). Mujeres Libres. España, 1936-1939. Barcelona: Tusquets.

Nash, M. (1981). Mujer y movimiento obrero en España, 1931-1939. Barcelona: Fontamara.
Nash, M. (1984). El neomalthusianismo anarquista y los conocimientos populares sobre control de natalidad en España. En Nash, M. (ed.). Presencia y protagonismo. Aspectos de la historia de la mujer. Barcelona: Serbal, pp. 307-340.

Nash, M. (1995). La reforma sexual en el anarquismo español. En: Hofmann, B.; Joan i Tous, P. y Tietz, M. (eds). El anarquismo español y sus tradiciones culturales. Frankfurt-Madrid: VervuertIberoamericana, pp. 281-296.

Nash, M. (1999). Rojas. Las mujeres republicanas en la guerra civil. Madrid: Taurus.

Navarro Monerris, J. (1988). Generación Consciente. Sexualidad y control de natalidad en la cultura revolucionaria española (Trabajo de investigación inédito). Instituto Juan Gil-Albert, Alicante.

Navarro Navarro, J. (1997a). El paraíso de la razón. La revista Estudios (1928-1937) y el mundo cultural anarquista. Valencia: Alfons el Magnànim.

Navarro Navarro, J. (1997b). Anarquismo y neomalthusianismo: la revista Generación Consciente (1923-1928). Arbor, CLVI, 615, pp. 9-23. http://dx.doi.org/10.3989/ arbor.1997.i615.1847

Navarro Navarro, J. (1997c). El camino hacia una cultura obrera de síntesis durante la II República: la revista Orto (1932-1934). Bulletin d'Histoire Contemporaine de l'Espagne, 26, pp. 535-551.

Navarro Navarro, J. (2004). A la revolución por la cultura. Prácticas culturales y sociabilidad libertarias en el País Valenciano (1931-1939). Valencia: Universitat de València.

Navarro Navarro, J. (2010). Los educadores del pueblo y la "revolución interior". La cultura anarquista en España. En Casanova, J. (ed.). Tierra y Libertad. Cien años de anarquismo en España. Barcelona: Crítica, pp. 191-217.

Noguera, E. y Huerta, L. (eds.). (1931). Genética, Eugenesia y Pedagogía Sexual. Libro de las Primeras Jornadas Eugénicas españolas, Madrid: Javier Morata Editor.

Paniagua, J. (1979). Educación y Economía en el sindicalismo de Marín Cive- ra. Valencia: Instituto de Ciencias de la Educación.

Paniagua, J. (1982). La sociedad libertaria. Agrarismo e industrialización en el anarquismo español, 1930-1939. BarceIona: Crítica.

Paniagua, J. (2001). Marín Civera y la cultura popular. Orto, 1932-1934. En: VV.AA. Orto (1932-1934). Revista de Documentación Social. Alzira-Valencia: Universidad Nacional de Educación a Distancia, pp. XV-LVIII.

Poch y Gascón, A. (1934). La cuestión del derecho a la vida. Orto, 20.

Relgis, E. (1933). Humanitarismo y eugenismo (I). Orto, 17.

Relgis, E. (1933). Humanitarismo y eugenismo (II). Orto, 18.

Relgis, E. (1934). La moral de la maternidad consciente. Orto, 20.

Roselló, J.M. (2003). La vuelta a la naturaleza. El pensamiento naturista hispano (1890-2000): naturismo libertario, trofología, vegetarismo naturista, vegetarismo social y librecultura. Barcelona: Virus.

Ruiz Pérez, J. (2004). Masonería y posibilismo libertario: la actividad masónica de Marín Civera. En: Ferrer Benimeli, J. A. (ed.). La masonería en Madrid y en España del siglo XVIII al XXI (vol. II). Zaragoza: Gobierno de Aragón, pp. 1005-1021.

Sinclair, A. (2007). Sex and Society in Early Twentieth Century Spain: Hildegart Rodriguez and the World League for Sexual Reform. Cardiff: University of Wales Press.

Varela, M.J. (1932). Sexo y educación. Orto, 4.

Vázquez García, F. y Moreno Mengíbar, A. (1997). Sexo y razón: una genealogía de la moral sexual en España (siglos XVI$X X)$. Madrid: Akal.

Vega, E. (2010). Pioneras y revolucionarias. Mujeres libertarias durante la República, la Guerra Civil y el Franquismo. Barcelona: Icaria. 